\title{
Use of a Blended Curricular Model of Autism-Specific Preparation and Professional Development for Increasing Educator Repertoires for Instructing Students with Autism Spectrum Disorders
}

\author{
Lisa Dille \\ Georgian Court University
}

\begin{abstract}
This review covers the research and development of use of a comprehensive curricular model of instruction and whether this model can be used to increase educator repertoires in instructing students with ASD. Specific focus was on the use of a blended model of autismspecific preparation and professional development in regard to increasing educator knowledge, educator selfefficacy, and use and application of instructional methods, strategies, and learning supports with students with ASD. The findings suggest that when the goals of autism-specific preparation and professional development are to specifically increase educator repertoires in knowledge of autism and educational treatments, selfefficacy and frequency of use of instructional methods, strategies, and learning supports with students with ASD, the blended curricular model of professional development for teaching students with ASD may be effective.
\end{abstract}

\section{Introduction}

ASD is one of the fastest growing disorders and one percent of the world population has the disorder and the prevalence in the US is estimated at 1 in 68 births [6]. Prevalence of the disorder has increased dramatically within ten years [3]. According to Centers for Disease Control and Prevention the prevalence of autism in U.S. children increased by 119.4 percent from 2000 (1 in 150) to 2010 (1 in 68) [6]. In 2014, the World Health Organization (WHO) adopted a formal resolution making autism a global health priority. This resolution is dedicated to supporting individuals by providing comprehensive and coordinated efforts to manage the disorder worldwide. The World Health Organization (WHO) ICD-10 Classification of Mental and Behavioural Disorders, defines autism as the presence of abnormal and/or impaired development manifesting before the age of three years and by the characteristic type of abnormal functioning in all three areas of social interaction, communication, and restricted, repetitive, and stereotyped patterns of behaviour [20].

The diagnostic characteristics of ASD are exhibited disparately across individuals and are therefore representative of the disorder being a spectrum disorder.

Copyright (c) 2014, Infonomics Society
As a spectrum disorder, autism is considered a heterogeneous disorder in which disparity occurs as variability of characteristics, symptoms, and behaviors in elevated patterns of occurrence, co-occurrence, and severity and therefore termed, Autism Spectrum Disorder (ASD) [1] [2] [3]. This heterogeneity of autism in which symptoms and characteristics in the areas of social interaction, communication, and restricted, repetitive, and stereotyped patterns of behavior manifest in a wide variety of combinations and degrees ranging from mild to severe [1] [2] [3] [20]. This heterogeneity has made it challenging to conduct research and generalize findings that are appropriate and effective educational treatments on an individual basis for individuals with ASD. Given the heterogeneous nature of the disorder a singular method that is either a behavioral approach or socioemotional approach may not be effective for a particular behavior, skill, or individual [3].

Due to the nature of the academic and learning needs of students with ASD, it is necessary that educators receive autism-specific preparation and professional development. Furthermore, preparation and professional development that addresses the learning needs of students with ASD as they age and transition into adolescence and adulthood is also needed. Implementation of any instructional method or intervention requires that educators be trained in its effective application to meet the needs of students with ASD and specifically the individual needs of each student with ASD. Although some educators may receive training in a specific singular method they are often not required to have specific training in evidence-based practices specifically designed for individuals with ASD. The teaching certifications required for teaching students with ASD vary according to each US state's specific requirements. Although some US states have added certification requirements which require specific university coursework to be completed in ASD others have minimized special education teaching certification requirements. In many US states, special education certifications are no longer a standalone certificate and teachers need to hold a general education certificate with an endorsement appropriate to the subject or grade level to be taught. This trend has further limited the qualifications of teachers for teaching students with ASD. Therefore, teachers may not have the instructional 
repertoire needed to address the heterogeneous learning needs of students with ASD. Due to the increase in prevalence of autism, the heterogeneity of the disorder, and the limitations of educator preparation, it is important to investigate whether providing autism-specific preparation and professional development for educators in an blend of various research-based methods and strategies in which to utilize in instructing students with ASD.

Traditionally, individuals with ASD have been treated educationally with singular teaching methods. Singular teaching methods are a specific method, which is devoted to, the implementation of specific teaching strategies and procedures within the educational setting. Some singular methods are Applied Behavior Analysis (ABA), Discrete Trial Training (DTT), TEACCH (Treatment and Education of Autistic and Communication Handicapped Children), Pivotal Response Training (PRT), and Incidental or Naturalistic teaching [4] [10] [11] [12] [13] [14] [15] [16] [19]. In addition there are singular methods, which have a socio-emotional basis such as Developmental Individual Difference, Relationship-Based (DIR) Model, and the SCERTS (Social Communication, Emotional Regulation, and Transactional Support) Model [9] [17] [18]. Although the behavioral approaches have been more dominant in practice, interventions which are developmentally based and focus on developing emotional regulation, support choice, and aim to increase autonomy such as Developmental Individual Difference, Relationship-Based (DIR) Model, and the SCERTS (Social Communication, Emotional Regulation, and Transactional Support) Model are increasingly popular [9] [17] [18].

The widespread national movement of inclusive education and use of the least restricted environments for individuals with ASD has contributed to the need for instruction which is not singular in nature, but is applicable and functional within school district settings. A central issue with use of singular teaching methods within school district settings is that it is difficult to implement a specific method due to the inclusiveness of the setting, the diverse needs of all students, the schedule of time, the requirements of educational standards and the diverse repertoires of the teachers within the setting. Due to limitations and the heterogeneity of the disorder, it is important to investigate whether multiple instructional methods can be blended into a comprehensive curricular model of instruction and whether this model can be used to increase educator repertoires in instructing students with ASD. Implementation of any method, strategy or intervention requires that educators receive preparation and professional development in its effective application to meet the needs of their students with ASD. Preparation and professional development in a blended curricular model of instruction may meet the need of increasing educator repertoires by providing them with a blend of instructional skills in which to utilize in teaching students with ASD.

\section{Review of the Blended Model}

Dille compared the effectiveness of two curricular models of instruction to increase teacher repertoires for instructing students with ASD [7]. Specific focus was on the use of a Blended Model of instruction in comparison to a Behavioral Model of instruction in regard to increasing educator knowledge, educator self-efficacy, educator self-report and educator application of instructional methods, strategies, and learning supports with students with ASD. The findings suggest that when the goal is to specifically increase teaching repertoires for applying instructional methods, strategies, and learning supports to students with both mild/moderate and severe autism the blending of both behavioral and socioemotional approaches for teaching students with ASD may be more effective.

The purpose of this study was to compare interventions designed to provide autism specific preparation and professional development to educators in a Blended Model of instruction versus a Behavioral Model of instruction. Specific focus was on the use of a Blended Model in comparison to a Behavioral Model in regard to increasing educator knowledge of ASD, educator self-efficacy of use of instructional methods, strategies and learning supports, educator self-report of use of instructional methods, strategies and learning supports, and educator application of instructional methods, strategies and learning supports with hypothetical cases of students with ASD. There were 48 participants in this study. All were educators recruited from various school districts and school settings throughout the northeast area of the US. Recruitment of educators was conducted by advertising with local school districts, educational agencies, and universities and included educators who taught in various settings including school-based specialized classes and programs, inclusion programs, preschool integrated school settings, center-based early intervention programs, and homebased programs. A screening questionnaire was administered to determine demographic variables for each participant.

The demographic characteristics measures were coded to form nine categorical variables. Equal numbers of subjects were randomly assigned to groups using a JavaScript random number generator. Pearson Chi-Square tests were conducted to compare groups on each of the categorical demographic variables. The results for each categorical demographic variable (level of education $\left(\chi^{2}=\right.$ $1.592,6 \mathrm{df}, \mathrm{p}=.953)$, years of teaching experience $\left(\chi^{2}=\right.$ $.821,6 \mathrm{df}, \mathrm{p}=.991)$, specialized training $\left(\chi^{2}=7.714,14\right.$ $\mathrm{df}, \mathrm{p}=.904)$, teacher certification $\left(\chi^{2}=.750,6 \mathrm{df}, \mathrm{p}\right.$ $=.991)$, type of disability taught $\left(\chi^{2}=1.872,10 \mathrm{df}, \mathrm{p}\right.$ $=.997)$, family member with disability $\left(\chi^{2}=.671,2 \mathrm{df}, \mathrm{p}\right.$ $=.715)$, age $\left(\chi^{2}=1.882,6 \mathrm{df}, \mathrm{p}=.930\right)$, gender $\left(\chi^{2}=.000\right.$, $2 \mathrm{df}, \mathrm{p}=1.000)$, and geographical location of teacher $\left(\chi^{2}=\right.$ $.263,4 \mathrm{df}, \mathrm{p}=.992$ ) were not statistically significant. All participants who completed the pretesting went on to 
complete the training and post testing for both groups. The independent variable of primary interest in this study was type of training. There were three groups in total with two being experimental groups and one a control group. One experimental group received training in the Blended Model of instruction and the other received training in the Behavioral Model of instruction. The Control group did not participate in training.

Specific research questions were: Do treatment groups differ significantly on posttest measures of (a) educator knowledge, (b) educator self-efficacy, (c) educator selfreport of use of instructional methods and strategies and learning supports, (d) educator application of instructional methods, strategies, and supports to hypothetical cases of students with ASD? Are there significant correlations between (a) teacher knowledge, (b) teacher self-efficacy, (c) teacher self-report of use of instructional methods and strategies and learning supports, (d) teacher application of instructional methods, strategies, and supports to hypothetical cases of students with ASD? Does application of instructional methods, strategies and supports by teachers differ significantly for students with mild/moderate and severe levels of ASD? Are there any significant interactions among the effects of type of treatment and severity of autism in terms of teacher application of instructional methods, strategies, and supports to hypothetical cases of students with ASD?

The results of this study supported the hypothesis that educators who received training in a Blended Model of instruction for teaching students with ASD increased their teaching repertoires. However, educators who received the Behavioral Model of instruction for teaching students with ASD also increased their teaching repertoires. Although the increase in teaching repertoires for the educators in the Behavioral group was limited to certain areas, there was still evidence supporting an overall increase in their teaching repertoires. Both the Blended group and the Behavioral group had scores that were significantly higher than the scores for the Control group on posttest measures of educator knowledge, educator self-efficacy, and educator self-report of use of instructional methods, strategies and learning supports. For the post test measures of educator knowledge, educator self-efficacy, and educator self-report, there were not significant differences between the Blended group and the Behavioral groups' scores, but the means for the Blended group were generally higher than those for the Behavioral group.

These findings are interesting in that there were not significant differences across experimental groups in regard to training in a singular behavioral approach and a blended approach of teaching which blended singular approaches together into one pedagogical approach to teaching students with ASD. The behavioral approaches that were blended were singular in that they were devoted to the implementation of specific teaching strategies and procedures within the educational setting. Both experimental groups obtained higher scores relative to the control group in the areas of educator knowledge of the diagnosis and classification of ASD, symptoms, and characteristics associated with the disorder, and educational approaches used for students with ASD, teaching self-efficacy of their knowledge and instructional skills in teaching students with autism, and the frequency of use of instructional methods, strategies, and learning supports with their students with ASD. It was suggested that both types of training enhanced educator's exposure and awareness of ASD and educating students with ASD which possibly led to the educators from both groups being highly motivated with stronger self-efficacy beliefs regarding their knowledge and instructional skills for teaching students with ASD and a greater tendency to use these instructional methods, strategies, and learning supports with their students.

In regard to correlations between educator knowledge, educator self-efficacy of their knowledge and instructional skills for teaching students with autism, educator self-report of use of instructional methods, strategies and learning supports, application of instructional methods, strategies, and learning supports to hypothetical cases, there were significant relationships. The strongest correlation was the relationship between post educator self-efficacy and post-educator self-report of use of instructional methods, strategies and learning supports. Participants that rated their efficacy of their knowledge and instructional skills in teaching students with ASD high also reported a high frequency of use of instructional methods, strategies, and learning supports with students with ASD. This finding suggests that educators who feel and believe they have the knowledge and instructional skills in teaching students with ASD are more likely to report that they utilize instructional methods, strategies, and learning supports with their students with ASD more frequently. This is supported by the additional correlation between post teacher knowledge and post-teacher self-efficacy which was also positive.

There was also a moderate positive correlation between post educators self-report of use and postapplication, suggesting that increased use of instructional methods, strategies, and learning supports with students with ASD may be directly related to the application of instructional methods, strategies, and learning supports to teach students with ASD. Also supporting this suggestion were the low positive correlations between post-educator knowledge and post-application and between post educator self-efficacy and post-application. An additional correlation, although also low, was post educator knowledge and post educator self-report of use which also suggests that when educators have the knowledge of the diagnosis and classification of autism, symptoms, and characteristics associated with the disorder and educational approaches that can be used for students with ASD the frequency of use of instructional methods, strategies, and learning supports with students with ASD increases. 
In regard to educator application of instructional methods, strategies and supports to students with mild/moderate versus severe levels of ASD there were no significant post-test differences or interactions between the two severity levels of autism. There was a significant pre-test difference between the two severity levels which disappeared on the post-test, largely because of the strong performance of the participants in the two intervention groups on items pertaining to both levels of severity. However, there was a significant difference between the two treatment groups on the overall application measure. The mean difference between the Blended group and the Behavioral group on posttest application of instructional methods, strategies, and supports to students with ASD was approximately nine points. This indicates that the Blended group did significantly better than the Behavioral group in applying instructional methods, strategies, and learning supports to teach students with ASD.

Dille expanded the investigation of the use and effectiveness of a blended curricular model of professional development to increase educator repertoires for instructing students with ASD [8]. This study was funded by a grant from the US Department of Health and Human Services, Health Resources and Services Administration (HRSA), Autism Training for Educational Staff in New Jersey: Autism Institute for Training and Applied Research. Specific focus was on the use of a blended model of professional development in regard to increasing educator knowledge, educator self-efficacy, educator self-report of use of instructional methods, strategies, and learning supports with students with ASD and educator application of instructional methods, strategies, and learning supports with students with ASD. The findings suggest that when the goals of professional development are to specifically increase educator repertoires in knowledge of autism and educational treatments, self-efficacy and frequency of use for applying instructional methods, strategies, and learning supports to students with ASD, the blended curricular model of professional development for teaching students with ASD may be effective.

This study aimed to address the need of increasing educator's repertoires in the areas of knowledge of autism, self-efficacy of use of instructional methods, strategies and supports, self-report of use of instructional methods, strategies and supports, and application of instructional methods, strategies and supports with students with ASD. Specific research questions were: Do participants pretest measures scores differ significantly from posttest measures scores of a) educator knowledge, b) educator self-efficacy, c) educator self-report of use of instructional methods and strategies and learning supports, d) educator application of instructional methods, strategies, and supports to hypothetical cases of students with ASD?; Does application of instructional methods, strategies and supports to hypothetical cases by educators differ significantly for students with mild/moderate and severe levels of ASD? Are there significant correlations between a) educator knowledge, b) educator self-efficacy, c) educator self-report of use of instructional methods and strategies and learning supports, d) educator application of instructional methods, strategies, and supports of students with ASD?

Recruitment of educators was conducted by advertising with local school districts, educational agencies, and universities and included educators who taught in various settings including school-based specialized classes and programs, inclusion programs, preschool integrated school settings, center-based early intervention programs, and home-based programs. A screening questionnaire was administered to determine demographic variables for each participant. The demographic characteristics measures were coded to form nine categorical variables.

Of the 159 participants registered for the training, 98 participants completed the screening questionnaire, the pretesting, the training and the post testing. In regard to level of education, 12 participants held a Bachelor's degree in special education, 9 participants were enrolled in a Master's degree program in special education, 4 participants were enrolled in a Master's degree program other than special education, 9 participants had completed a Master's degree in special education, 42 participants held a Master's degree in fields other than special education, 9 participants held a doctorate degree and 13 participants held a high school diploma.

In regard to years of experience teaching in special education, 24 participants had 1-5 years teaching experience, 13 participants had 6-11 years of teaching experience, 19 participants had 12 or more years of teaching experience, 18 participants had teaching experience in a discipline other than special education, 24 participants did not have teaching experience. In regard to specialized training previously received in working with individuals with autism, 16 participants had completed training in workshops in TEACCH, 17 participants had completed extensive training in TEACCH, 48 participants had completed training in workshops in Applied Behavior Analysis (ABA), and 17 participants had completed extensive specialized training in $\mathrm{ABA}$. In regard to teaching and professional certification status, 22 participants did not have a teaching certification, 3 participants had applied for initial certification in special education, 3 participants had an initial certification in special education, 19 participants had a permanent certification in special education, 34 participants had other teaching certifications and/or professional licenses in the field of education, and 17 participants did not have a teaching certification and/or professional license.

In regard to type of disability and previous experience and or knowledge of, 7 participants identified learning disability, 2 participants identified physical or mobility disability, 3 participants identified intellectual disability, 2 participants identified autism or PDD, 7 participants identified other disabilities and 77 participants identified themselves and not having previous experience or 
knowledge of a disability. In regard to having a family member with a disability, 50 participants did not have a family member with a disability and 48 participants did have a family member with a disability. In regard to the age range of the 98 participants, 19 participants were 21 26 years old, 8 participants were 27-32 years old, 11 participants were 33-40 years old, 60 participants were $41+$ years old. In regard to gender, 94 participants were female and 4 were male. In regard to geographical location, 21 participants lived in an urban setting, 75 participants lived in a suburb setting, and 2 participants lived in a rural setting.

Participants completed the preassessment prior to beginning the training sessions and a post assessment which was the same as the preassessment upon completion of the training sessions. Participants of the training were provided with twelve sequential sessions. The first six sessions were held one Saturday per month during the academic year, with the six additional sessions held on weekdays during the summer months. The professional development included presentations and workshops by top professionals in the field of autism and leading researchers and experts on various subjects related to education and intervention of individuals with ASD. Participants also received various instructional materials including textbooks and DVDs related to each session topic at the completion of each training session. Sessions were held in a lecture hall on campus of the principal investigator's university. The time of each session was 8:30am -3:30 pm. Lunch was provided to each participant. The specific schedule was as follows:

Session 1: Nature and Needs of Individuals with ASD

Session 2: Assessment and Programming Planning for Autism Spectrum Disorders

Session 3: Understanding and Intervening of the

Social Communication Needs of Children and Adolescents with ASD

Sessions 4 and 5: Applied Behavior Analysis (ABA) and Verbal Behavior Interventions for Children and Adolescents with ASD

Session 6: Integrating Academic and Life Skills into the Daily Curriculum for Children and Adolescents with ASD with ASD

Session 7: Transition Planning for Adolescents

Session 8: Asperger's Syndrome

Session 9-12: Putting Research into Practice: Educating Adolescents with Autism Spectrum Disorders

Assessment instruments (Educator Knowledge of Autism and Educational Treatment of Autism Questionnaire, Educator Self-Efficacy of Use of Instructional Methods, Strategies, and Supports for Students with Autism, Educator Self-Report of Use of Instructional Methods, Strategies and Supports for Students with Autism, and Performance Assessment of
Application of Instructional Methods, Strategies, and Supports to Teach Students with Autism were initially developed by the researcher based on literature about each treatment approach and were also used in the previous study of increasing educator's repertoires for instructing students with ASD. To test for face validity all four assessments were presented to thirteen reviewers including teachers, clinicians, and experts experienced in both behavioral and socio-emotional approaches of instructing students with autism. Reviewers shared and aided in the revision of each item of all four assessments. Revisions made each item and assessment more specific to each dependent variable of the study. To determine validity and reliability for testing measures a split-half reliability and coefficient alpha was computed.

To measure educator knowledge, the Educator Knowledge of Autism and Educational Treatment of Autism Questionnaire was used. The questionnaire consists of 30 multiple-choice questions. Each question was answered with either a correct response or an incorrect response and a dichotomous scale $(1=$ correct response and $0=$ incorrect response) was used to score responses. The maximum score for this assessment was 30 points. In summary for Teacher Knowledge the splithalf reliability was .77, and coefficient alpha was .846 .

To measure educator self-efficacy, the Educator SelfEfficacy of Use of Instructional Methods, Strategies, and Supports for Students with Autism, was administered. This instrument is a 31-item checklist in which each item was answered and rated using a Likert scale. Scoring is as follows: 3=I feel I have the knowledge and skills needed, $2=\mathrm{I}$ feel I have some knowledge and skills needed in this area, $1=\mathrm{I}$ feel knowledgeable in this area but I do not feel I have the skills needed, $0=\mathrm{I}$ do not feel knowledgeable or skilled in this. The maximum score for this assessment was 93 points. In summary on use of instructional methods and strategies and learning supports as measured by the self-efficacy instrument, the split-half reliability was .94, and coefficient alpha was .97.

To measure educator self-report of use of instructional methods, strategies, and supports the Educator SelfReport of Use of Instructional Methods, Strategies and Supports for Students with Autism was administered. This instrument was a 30-item checklist in which each item was answered and rated using a Likert scale. Scoring was as follows: 4=Always, $3=$ Most of the time, $2=$ Sometimes, $1=$ Rarely, $0=$ Never. The maximum score for this assessment was 120 points. In summary on use of instructional methods and strategies and learning supports as measured by the self-report instrument, the split-half reliability was .94, and coefficient alpha was .97 .

To measure educator application of instructional methods, strategies, and supports with students with mild autism versus use with students with severe autism the Performance Assessment of Application of Instructional Methods, Strategies, and Supports to Teach Students with Autism was administered. This instrument measured application of instructional methods, strategies, and 
supports to teach students identified as having autism in the mild to moderate range versus the moderate to severe range. This instrument consisted of four case studies in which two depict hypothetical students with mild to moderate autism and two case studies depict students in the moderate to severe range. A consistent set of six questions across all four case studies which were designed to measure the capacity to apply instructional methods, strategies, and supports with students with autism were presented. Responses were categorized as follows: $0=$ Response indicates insufficient understanding, no appropriate answers, and/or major errors. 1= Response indicates limited understanding, is incomplete, and/or contains major errors. 2=Response indicates substantial and appropriate understanding but may have minor errors. $3=$ Response is correct and the underlying reasoning process is appropriate and clearly communicated. Response may contain minor errors if any. The four case studies and their corresponding questions were grouped into two categories: mild and severe. Each category received a categorical score. The maximum score for each category was 36 points. Both scores were totaled yielding one composite score for a grand total. The maximum score for this assessment was 72 points. In summary the Performance Assessment of Application of Use of Instructional Methods, Strategies, and Supports the splithalf reliability was .88 , and the coefficient alpha was .95 .

The results on the effects of the training indicated that participants' knowledge post-test mean scores increased significantly. The mean score for all participants on the knowledge pre-test was $(M=17.64)$, with a minimum score on the pre-test of 0 and a maximum score on the pre-test of 30. After the intervention the mean score for all participants on the knowledge post-test was $(M=25.62)$, with a minimum score on the post-test of 15 and a maximum score on the post-test of 30 . Results are displayed in Table 1.

According to these results after participants received the introductory and foundational knowledge of ASD and educational interventions used to treat ASD there was an overall mean score increase of 8 points from the knowledge pre-test to post-test.

The data on the effects of the training indicates that participants' self-efficacy post-test mean scores increased significantly. The mean score for all participants on the self-efficacy pre-test was $(M=37.02)$, with a minimum score on the pre-test of 0 and a maximum score on the pre-test of 89. After the intervention the mean score for all participants on the self-efficacy post-test was $(M=82.88)$, with a minimum score on the post-test of 31 and a maximum score on the post-test of 93 . There was a mean increase of 45.86. Significant in these findings are that 26 participants scored between 86 and 90, while 38 participants scored a 93, indicating that $64 \%$ of the participants felt they gained the knowledge and instructional skills needed to teach students with ASD. Results are displayed in Table 1.
The data on the effects of the training indicates that participants' self-report post-test mean scores increased significantly. The mean score for all participants on the self-report pre-test was $(M=36.97)$, with a minimum score on the pre-test of 0 and a maximum score on the pre-test of 100. After the intervention the mean score for all participants on the self-report post-test was $(M=78.95)$, with a minimum score on the post-test of 3 and a maximum score on the post-test of 93. After the participants completed the training, the self-report of the use of instructional methods, strategies, and learning supports mean score increased to 45.86. Results are displayed in Table 1.

The data on the effects of the training indicates that participants' application post-test mean scores increased significantly. The mean score for all participants on the application pre-test was $(M=85.45)$, with a minimum score on the pre-test of 0 and a maximum score on the pre-test of 216. After the intervention the mean score for all participants on the application post-test was $(M=163.66)$, with a minimum score on the post-test of 4 and a maximum score on the post-test of 236. After participants completed the training, the application of instructional methods, strategies, and supports for students with ASD mean score increased to 78.21. Results are displayed in Table 1.

In regard to correlations between knowledge, selfefficacy, self-report of use of instructional methods, strategies and supports, and application of instructional methods and strategies and learning supports to hypothetical cases, a correlation matrix was calculated to determine if there were any significant relationships

\section{Table 1 Means and Standard Deviations (SD) for Pre \& Post Test}

\begin{tabular}{lllll} 
Scale & $\begin{array}{l}\text { Post- } \\
\text { Teacher } \\
\text { Knowledge }\end{array}$ & $\begin{array}{l}\text { Post- } \\
\text { Self } \\
\text { Efficacy }\end{array}$ & $\begin{array}{l}\text { Post- } \\
\text { Appl. }\end{array}$ & $\begin{array}{l}\text { Post- } \\
\text { Self } \\
\text { Report }\end{array}$ \\
$\begin{array}{l}\text { Post- } \\
\text { Knowledge }\end{array}$ & 1 & .045 & .050 & .007 \\
$\begin{array}{l}\text { Post- } \\
\text { Efficacy }\end{array}$ & & 1 & .204 & .498 \\
$\begin{array}{l}\text { Post- } \\
\text { Performance }\end{array}$ & & & 1 & .197 \\
$\begin{array}{l}\text { Post- } \\
\text { Report }\end{array}$ & & & & 1 \\
\hline
\end{tabular}

between the independent and dependent variables. The correlation coefficient between the variables postknowledge and post-efficacy $(r=.045)$ suggest a low positive relationship. An $r$ value of .045 indicated that there was a chance that as knowledge increased, selfefficiency tended to increase. The correlation coefficient of between the variables, post-knowledge and postapplication ( $r=.050)$ suggest a low positive relationship. An $r$ value of .050 indicated that there was a chance that as knowledge increased application of instructional 
methods, strategies, and supports for students with ASD tended to increase. The correlation coefficient between the variables post-knowledge and post-report ( $r=-.007)$ suggest a low negative relationship. An $r$ value of .050 indicates that there is a chance that as knowledge increased, self-report of the use of instructional methods, strategies, and learning supports tended to decrease. The correlation coefficient between the variables post-efficacy and post-application $(r=.204)$ suggest a low positive relationship. An $r$ value of .204 indicated that there was $4 \%$ chance that as self-efficacy increased, application of instructional methods, strategies, and supports for students with ASD tended to increase. Results are displayed in Table 2.

\section{Table 2 Correlation Matrix of Independent and Dependent Variables}

\begin{tabular}{|c|c|c|}
\hline $\begin{array}{l}\text { Pre \& Post } \\
\text { Test }\end{array}$ & $\mathrm{M}$ & SD \\
\hline $\begin{array}{l}\text { Pre-test } \\
\text { Educator } \\
\text { Knowledge }\end{array}$ & 17.64 & 4.80 \\
\hline $\begin{array}{l}\text { Post-test } \\
\text { Educator } \\
\text { Knowledge }\end{array}$ & 25.62 & 3.53 \\
\hline $\begin{array}{l}\text { Pre-test Self } \\
\text { Efficacy }\end{array}$ & 37.02 & 26.77 \\
\hline $\begin{array}{l}\text { Post-test Self } \\
\text { Efficacy }\end{array}$ & 82.88 & 15.60 \\
\hline $\begin{array}{l}\text { Pre-test Self } \\
\text { Report }\end{array}$ & 36.97 & 33.56 \\
\hline $\begin{array}{l}\text { Post-test Self } \\
\text { Report }\end{array}$ & 78.95 & 20.60 \\
\hline $\begin{array}{l}\text { Pre-test } \\
\text { Educator } \\
\text { Application }\end{array}$ & 85.45 & 65.99 \\
\hline $\begin{array}{l}\text { Post-test } \\
\text { Educator } \\
\text { Application }\end{array}$ & 163.66 & 51.37 \\
\hline
\end{tabular}

The correlation coefficient between the variables, post-application and post-report $(r=.197)$ suggest a low positive relationship. An $r$ value of .197 indicated that there is $4 \%$ chance that as application of instructional methods, strategies, and supports for students with ASD increased, self-report of the use of instructional methods, strategies, and learning supports tended to increase. The correlation coefficient between the variables post-efficacy and post-report was significant at the 0.01 level (2-tailed).
What this signifies is that 99 times out of a hundred the relationship found between the variables post-efficacy and post-report will exist. The correlation coefficient between the variables post-efficacy and post-report ( $r=.498)$ suggest a moderate positive relationship. An $r$ value of .498 indicates that there is a $24 \%$ chance that as participants' self-efficacy increased, participants selfreport of the use of instructional methods and strategies and learning supports tended to increase. Results are displayed in Table 2.

In regard to application, there was no significance difference between application of instructional methods, strategies, and learning supports when applied to students with mild to moderate range versus the moderate to severe range of ASD.

\section{Discussion}

The findings of these studies suggest that singular approaches that are devoted to the implementation of specific teaching strategies and procedures within the educational setting may not provide educators with the skills needed to apply instructional methods, strategies, and supports to a range of situations in the instructional setting. It is suggested that socio-emotional components when blended with behavioral approaches provides educators with a more comprehensive repertoire of instructional methods, strategies, and learning supports to apply in the instructional setting with students with ASD. This may be because the blending of both types of approaches provides educators with an approach that is a broader and a more comprehensive curricular model of instruction they can utilize to meet the heterogeneous learning needs of students with ASD.

Implementation of any instructional method or intervention requires that educators be trained in its effective application to meet the needs of students with ASD. Although some educators may receive training in a specific singular method they are often not required to have specific training in evidence-based practices specifically designed for individuals with autism. The teaching certifications required for instructing students with ASD vary according to each state's specific requirements. Although some states have added certification requirements which require specific university coursework to be completed in autism others have minimized special education requirements. This trend has further hastened the need for investigating the use of autism-specific preparation and professional development of educators for teaching students with ASD and effectively addressing the heterogeneous learning needs of students with ASD.

The results of these studies supported the hypothesis that educators who received training with a blended curricular model of professional development increased their repertoires for instructing students with ASD. Specifically they increased their knowledge of autism and 
educational treatment of autism, their self-efficacy of use of instructional methods, strategies, and supports for students with ASD, and the frequency of self-reported use of instructional methods, strategies and supports for students with ASD. Interestingly, although the application of instructional methods, strategies, and supports for students with ASD did increase there was not a difference in application to students with mild autism versus use with students with severe autism. These findings indicated that participants applied the instructional methods, strategies, and learning supports for students with ASD to both students identified as having ASD in the mild to moderate range and students identified as having ASD in the moderate to severe range.

In regard to correlational findings between the variables of knowledge, self-efficacy, self-report of use of instructional methods, strategies and supports, and application of instructional methods and strategies and learning supports several relationships were suggested by the findings [8]. The correlation findings between postknowledge and post-efficacy suggested a positive relationship indicating that there is a chance that as participant knowledge increased, participant self-efficacy tended to increase. These findings seem self-explanatory as it would seem that as the participants' knowledge increased their efficacy of use of instructional methods, strategies, and supports for students with ASD increased. The correlation findings between post-knowledge and post-application also suggested a positive relationship. This suggests that there is a chance that as knowledge of autism and educational treatments increased actually applying the instructional methods, strategies, and supports for students with ASD tended to increase. This would suggest that participants were actually implementing the instructional methods, strategies, and supports for students with ASD in which they were trained in and included in the professional development sessions.

The correlation findings between post-knowledge and post-report were interesting as they suggested a negative relationship [8]. This finding may indicate that as knowledge increased, self-report of the use of instructional methods, strategies, and learning supports tended to decrease. This may be attributed to the increase in the knowledge and understanding of the accuracy and correctness of instructional methods, strategies, and learning supports for students with ASD. This may have attributed to the decrease in self-reporting of use instructional methods, strategies, and learning supports for students with ASD because participants did not report they were using a particular instructional methods, strategies, and learning supports if they had not applied it correctly.

The correlation findings between post-efficacy and post-application suggested a positive relationship [8]. These findings indicated that as self-efficacy increased, application of instructional methods, strategies, and supports for students with ASD tended to increase. This could be contributed to that as the participant's belief and confidence in the instructional methods, strategies, and supports for students with ASD increased the more they applied them with their students with ASD. The correlation findings between post-application and postreport suggested a positive relationship. This indicated that as application of instructional methods, strategies, and supports for students with ASD increased, self-report of the use of instructional methods, strategies, and learning supports tended to increase. This would indicate that as participants increased their ability to apply instructional methods, strategies, and supports for students with ASD, they then increased their use of applying these instructional methods, strategies, and supports. The correlation findings between post-efficacy and post-report was significant and suggested that a positive relationship existed. This finding was most significant and suggested that as participant's selfefficacy increased they reported that they used the instructional methods and strategies and learning supports more.

These studies examined several different variables that have not been previously studied in educators of students with ASD. Continued research in this area should focus on conducting future studies with a larger sample, more extensive training for participants, inclusion of a component which links findings to student achievement, inclusion of a qualitative component, and inclusion of participants from various regions and internationally. In regard to replicating the study with a larger sample this could allow for the more sensitive detection of other possible differences in the impact of the different training approaches. In regard to increasing the amount of training, more extensive training would provide further information which may produce increased teaching repertoires. There were also limitations in the areas of funding and methodology. This study's funding was limited to implementing one treatment to a relatively large group. Future research should focus on implementing a blended curricular model of autism- specific preparation and professional development to increase educator repertoires for instructing students with ASD using a pre/post group comparison design and have larger control and comparison groups. Overall, the findings of these studies indicated that educators can increase their knowledge of autism and educational treatment of autism, their self-efficacy of use of instructional methods, strategies, and supports for students with ASD, the frequency of self-reported use of instructional methods, strategies and supports for students with ASD and the application of instructional methods, strategies and supports to all students with ASD through use of a blended curricular model of autism-specific preparation and professional development. 


\section{References}

[1] American Psychiatric Association (1994). Diagnostic and Statistical Manual of Mental disorders $\left(4^{\text {th }} \mathrm{Ed}\right.$.). Washington, DC: Author.

[2] American Psychiatric Association (2013). Diagnostic and Statistical Manual of Mental disorders $\left(5^{\text {th }}\right.$ Ed.). Washington, DC: Author.

[3] Autism Society of America (ASA). (2005). What are autism spectrum disorders? Retrieved February 7, 2007 from http://www.autism-society.org

[4] Baer, D. M., Wolf, M. M., \& Risley, T. R. (1968). Some current dimensions of applied behavior analysis. Journal of Applied Behavior Analysis, 1, 91-97.

[5] Center for Disease Control and Prevention (CDC) (2007). Autism Spectrum Disorders Overview. Washington, DC: Department of Health and Human Services.

[6] Center for Disease Control and Prevention (CDC) (2014). Community Report on Autism. Washington, DC: Department of Health and Human Services.

[7] Dille, L. (2013). A Comparison of Two Curricular Models of Professional Development to Increase Teacher Repertoires for Instructing Students with Autism. Journal of the American Academy of Special Education Professionals (JAASEP), Fall 2013.

[8] Dille, L. (2012). Using a Blended Curricular Model of Professional Development to Increase Educator Repertoires for Instructing Students with Autism. International Journal of Humanities and Social Science, Vol. 2, No. 21, 40-47.

[9] Greenspan, S., \& Weider, S., (1997). The Child with Special Needs: Encouraging Intellectual and Emotional Growth. Addison Wesley: NYC.

[10] Hart, B. M., \& Risley, T. R. (1968). Establishing the use of descriptive adjectives in the spontaneous speech of disadvantaged children. Journal of Applied Behavior Analysis, $1,109-120$

[11] Hart, B. M., \& Risley, T. R. (1974). Using preschool materials to modify the language of disadvantaged children. Journal of Applied Behavior Analysis, 7, 243-256.

[12] Hart, A. P., \& Risley, T. R., (1980). In vivo language training: Unanticipated general effects. Journal of Applied Behavior Analysis, 13, 407-437.

[13] Koegel, R.L. \& Schreibman, L. (1977). Teaching autistic children to respond to simultaneous multiple cues. Journal of Experimental Child Psychology, 24, 299-311.

[14] Koegel, R. L., \& Koegel, L. K. (2006). Pivotal Response Treatments for Autism. Baltimore, MD: Paul H. Brookes.

[15] Lovaas, O.I. (1987). Behavioral treatment and normal educational and intellectual functioning in young autistic children. Journal of Consulting and Clinical Psychiatry, 55, 3-9.

Copyright (c) 2014, Infonomics Society
[16] McEachin, J. J., Smith, T., \& Lovaas, O. I. (1993). Longterm outcome for children with autism who received early intensive behavioral treatment. American Journal of Mental Retardation, 97, 359-372.

[17] Prizant, B.M., Wetherby, A.M., Rubin, E., Laurent, A.C., \& Rydell, P. (2002). The SCERTS model: Enhancing communication and socio-emotional abilities of children with autism spectrum disorders. Jenison Autism Journal, 14, 2-19.

[18] Prizant, B.M., Wetherby, A.M., Rubin, E., Laurent, A, C., and Rydell, P. (2006). The SCERTS Model: Volume I \& II. Baltimore, MD: Brookes Publishing.

[19] Schopler, E., Mesibov, G.B., \& Hearsey, K. (1995). Structured teaching in the TEACCH system. In Schopler, E. and Mesibov, G.B. (Eds.) Current Issues in Autism: Learning and Cognition in Autism. New York: Plenum.

[20] World Health Organization (WHO), (1992). The ICD-10 classification of mental and behavioral disorders: clinical descriptions and diagnostic guidelines. Geneva: WHO. 